\title{
Trabalho e esperança em 2020
}

\author{
Suzana Guerra Albornoz ${ }^{1}$ \\ Universidade Federal do Rio Grande (Rio Grande, RS, Brasil)
}

\begin{abstract}
Este ensaio parte do conceito elaborado por Ernst Bloch (1885-1977) de que a esperança se enraíza nas possibilidades inseridas na realidade. Quando se insere a esperança de reconhecimento do direito dos trabalhadores a maior dignidade nas transformações técnicas e lutas sociais da era industrial, mostra-se a união de esperança e trabalho, presente nas contradições dos tempos modernos pelo mundo e no Brasil. Em nossa atual situação crítica, na enfermidade mundial; quando as sociedades evoluem para tecnológicas, diminui a demanda de operários na indústria e desaparece a garantia de emprego estável; a humanidade é desafiada a refletir sobre sua atividade que transcende o trabalho produtivo material e a inventar soluções da ordem da esperança, utopias concretas, não impossíveis de realizar.
\end{abstract}

Palavras-chave: Trabalho, Esperança, Realidade e possibilidades.

Work and hope in 2020

This essay begins by remembering the concept wrought by Ernst Bloch $(1885-1977)$ that hope's root is in the possibilities within reality. The technical changes and social struggles in the industrial era showed the hope of recognition of worker's rights of better conditions of life and more dignity, so that it's to say that hope and work have been straight together in the contradictions of modern times, in the world as in Brazil. At this critical moment of a pandemia; when societies go into technological and the demand of workers at industry decrease, and when almost disappear the confidence on stable employments, humanity has the challenge to reflect about its activity - what transcend the material productive work, and have to invent solutions, even if it seam to belong to the order of hope as concrete utopias, but are not impossible to make real.

Keywords: Work, Hope, Reality and possibilities.

\section{Introdução}

\begin{abstract}
A lguém disse que a cor da esperança é o negro, e essa afirmação me fez pensar. Ignoro quem o afirmou pela primeira vez, mas quem o repetiu parecia indicar que a esperança acompanha o movimento dos negros por sua afirmação, contra o racismo, essa terrível chaga que, em nosso país e em todo o continente americano - de Norte a Sul -, infelizmente em grande parte do planeta, demonstra forte atualidade. Por isso, aquela afirmação me pareceu correta já por esse significado, mas talvez o autor da afirmação de que a cor da esperança é o negro tivesse também a intenção de sugerir que ela se esconde ou disfarça na escuridão do momento obscuro para, ao captar luz, brilhar. Pode-se também ver ali uma alusão à estrela, que brilha mais quando a noite é escura, sem luar. É por certo difícil falar de algo que se esconde na sombra e aparece como por contraste. Talvez seja por isso que poetas e, às vezes, também filósofos, abusam das metáforas a seu respeito e, para dizer esperança, nomeiam o amanhecer, a aurora, o nascer do dia, ou referem-se à luz que aparece no fim do túnel. Por tudo isso, está claro que não podemos dizer nada como uma palavra completa, última sobre a esperança, pois tateamos no território impreciso da luz do amanhecer, do lusco-fusco, no obscuro do momento presente.

No século XX, o filósofo Ernst Bloch, sobre quem falei muitas vezes e escrevi alguns textos de apresentação para o público leitor brasileiro ${ }^{2}$, defendeu a importância e a força de realidade da

1 https://orcid.org/0000-0002-2431-8617

2 Ver, especialmente, "Ética e utopia" (Albornoz, 1985) e "O enigma da esperança: Ernst Bloch e as margens da história do espírito" (Albornoz, 1999); mas é também em torno de Bloch "Violência ou não violência" (Albornoz, 2000).
\end{abstract}


esperança como da utopia. Bloch meditou persistentemente sobre a história das utopias, construindo um sistema filosófico em torno da esperança, um sistema aberto, de erudição imensa, que se expõe em um oceano de páginas de grande inspiração literária. E, ao longo de sua extensa obra, trabalhou um novo conceito de utopia que presta reconhecimento aos sonhos humanos coletivos e atribui relevância prática ao que chamou de utopia concreta, ou seja, às antecipações e lutas históricas em prol do novo, daquilo que ainda não é, contudo, pode vir a ser. Tais sonhos coletivos não são devaneios estéreis, são elaboração das possibilidades do real; as utopias indicam o ainda não ser, o possível contido no existente atual; e, ao ainda não ser, da possibilidade real, se deve a esperança.

Sobretudo na enciclopédia das utopias intitulada "Princípio esperança", mas também em todos os outros livros de sua longa e fecunda produção, Ernst Bloch desenvolveu, fundamentou e exemplificou, exaustivamente, o conceito de utopia concreta, que não é algo impossível como está suposto no conceito vulgar de utopia, ao contrário, trata-se de uma elaboração das possibilidades do mundo real concreto como promessas para o futuro. Na concepção de utopia concreta inserida na possibilidade real, o conceito de esperança se torna peculiar, entendido, a esperança, como um dado antropológico, uma dimensão, uma capacidade própria do ser humano. A esperança que perpassa a história da humanidade não tem apenas o sentido de uma disposição afetiva ou estado de ânimo; não é somente um sentimento ou virtude, mas um fenômeno cognitivo. É da ordem do que entendemos por profecia ou premonição, ou melhor, como previsão ou prognóstico, pois antecipa e aponta para aquilo que hoje ainda não é, mas está dado como possibilidade, pode vir a ser, dependendo apenas da intervenção da liberdade humana para efetivar-se em seus movimentos coletivos. Portanto, a esperança tem um caráter cognitivo e é um indicador do possível no futuro. Por isso, é uma questão prática muito relevante ouvir e entender esperanças.

\section{Trabalho e esperança nos tempos modernos}

Ao considerar, em particular no Ocidente, a história econômica, social e política dos últimos séculos, percebe-se que esperança e trabalho têm andado juntos nesse período que chamamos de tempos modernos e coincide com a história do Brasil depois da chegada dos europeus ${ }^{4}$. Na época moderna chamada de era industrial, entendida como civilização do trabalho, a esperança dos povos - e, em grande parte, a dos indivíduos - foi muitas vezes associada ao exercício de uma arte ou um trabalho expressivo, proveitoso e digno. As utopias concretas da era do trabalho estiveram estreitamente ligadas à luta dos trabalhadores em busca da sobrevivência, por reconhecimento e pelo direito a condições dignas de trabalho e vida. Aposto que essa ainda é a esperança mais concreta da maioria dos nossos contemporâneos pelo planeta, assim como no Brasil destes dias, com todas as suas confusões.

Do século XVIII ao XXI e, intensamente, nos séculos XIX e XX, em diversas proporções, o trabalho sofreu fortes transformações graças ao desenvolvimento da ciência e da técnica e das ideias que as acompanharam ${ }^{5}$. A revolução que, no século XVIII, fora a máquina a vapor, de certa forma, foi continuada e superada pela invenção da eletricidade no século XIX; e, no século XX, impuseram-se muitas outras inovações que influenciaram o mundo produtivo, especialmente a extraordinária invenção que se pode chamar de revolução cibernética, com a entrada em cena

3 O princípio esperança não é a única obra de Ernst Bloch que esclarece o seu original conceito de utopia concreta e o de esperança, mas é a sua obra prima, traduzida para o Brasil em 2005 e 2006. Nas referências indico algumas coletâneas sobre o autor publicadas recentemente entre nós: Bloch (2005, 2006a, 2006b).

4 Em "Trabalho e utopia na modernidade" (Albornoz, 2011), tanto na Introdução como nos textos que, de 2003 a 2008, foram publicados nos CPST, abordei alguns autores do pensamento utópico sobre o trabalho.

5 A leitura de "O que é trabalho" (Albornoz, 1986) pode ser útil. 
dos computadores e da inteligência artificial. A cada vez, as máquinas substituem trabalho braçal e atingem empregos nessas passagens das invenções técnicas, quando se criam novas situações e necessidades, e por elas caminham as questões sociais, surgindo conflitos árduos, mas também novas esperanças, de melhoria das condições de vida e de mudança nas relações sociais. O calvário tantas vezes criminoso que tem sido, ao longo da história humana, a exploração do trabalho dos prisioneiros, dos escravizados, dos mais frágeis tem alimentado a esperança ante a transformação da técnica e dos meios de produção. E, junto a esses movimentos de transformação técnica, continuaram as lutas dos trabalhadores por melhores condições de trabalho, novos direitos, maior respeito e dignidade de vida. Nem sempre com êxito, com muitas dificuldades, muita luta, com sacrifícios imensos, avanços e retrocessos, mas também com conquistas evidentes.

Na civilização, cultura e ideologia, quase se poderia dizer na religião do trabalho da era industrial - de Lutero a Marx -, em oposição aos interesses burgueses individualistas e capitalistas, a esperança contrapôs a classe operária aos poderes que têm determinado a sua exploração, ao ponto de que algumas revoluções políticas experimentaram a instauração de novas estruturas e novas dinâmicas de relação entre as classes sociais e, em determinado período do século XX, a transformação do lugar dos trabalhadores manteve-se no horizonte da esperança, realizando-se experiências econômicas, sociais e políticas importantes nessa direção, ainda que não tenha havido sempre avanço, tampouco uma alternativa simples entre socialismo e capitalismo.

O desenvolvimento do trabalho na era industrial, portanto, foi acompanhado da esperança de emancipação da classe trabalhadora, com evidentes imbricações das lutas operárias com outros movimentos de emancipação, como o das mulheres, o dos grupos raciais oprimidos e o dos povos colonizados. No último século, confrontaram-se e conviveram, com maior ou menor grau de conflito ou tolerância, democracias liberais, social-democracias, democracias populares, ditaduras capitalistas, fascistas, coletivistas e experiências mais difíceis de classificar. A criatividade utópica deixou sua marca em um universo geopolítico, econômico e social marcado pela luta de classes, a violência, o excesso e a falta.

Durante o período da Guerra Fria, após a II Guerra Mundial, a alternativa existente - pelo menos de 1945 a 1989, do final da guerra contra o nazismo até a queda do muro de Berlim - apresentava-se, de um lado, um bloco de países socialistas, com Estados fortes e prioridade na organização da vida produtiva e das massas trabalhadoras, embora nem sempre respeitadores dos ditames do estado de direito e das liberdades burguesas. Do outro lado, por competição e pressão, efetivou-se também certa evolução dentro do mundo capitalista, favorecendo a organização de Estados de bem-estar social, como os da Europa ocidental, com conquistas de uma série de direitos à educação, à saúde, à organização sindical, à proteção social e à participação política pelos trabalhadores.

A utopia concreta predominante na era industrial, em diferentes proporções de um lado e do outro da "cortina de ferro", parece ter sido a do socialismo com humanização do trabalho e melhoria da vida dos trabalhadores, ainda que tenham sido também intensas as lutas anticolonialistas frente à Europa, as dos direitos civis dos negros na América do Norte e as da liberação sexual e emancipação das mulheres. A nova vaga de neoliberalismo econômico que se impôs fortemente no mundo capitalista a partir da década de 1970, que perderia o seu contraponto geopolítico em 1989, atingiu, de modo ainda não bem dimensionado, utopias e ideologias que animavam o movimento operário e suas formas de participação política no período anterior.

\section{Trabalho e esperança no Brasil}

O Brasil andou devagar na questão social do trabalho e nas lutas dos trabalhadores. Três séculos de colonização portuguesa nos haviam transformado em imenso produtor de riquezas para 
o estrangeiro, que também se mostrou sob outras bandeiras; e a produção se efetivou de modo desumano e vexatório, pela exploração do trabalho escravo - primeiro, do escravo indígena, depois, em grande escala, do escravo africano, e assim continuou por muito tempo após a Independência. Este texto breve não permite revisarmos mais atentamente essa terrível e triste história, infelizmente ainda não bem contada nem superada, mas que não se fique inteiramente em silêncio para que, ao lembrá-la, indique-se a necessidade de pesquisa e reflexão. Vindos desse longo tempo de experiências muito contrárias à democracia e à humanização do trabalho, depois de longo período de colonização e ainda mais tempo de escravidão, a República no Brasil dava os primeiros passos na entrada do século XX.

A partir de 1930 parecem ocorrer no Brasil alguns avanços no sentido da modernização da vida social e política, quando nossos conflitos tentam acertar passo com os do mundo moderno, mas, ainda assim, embora algumas conquistas se tenham efetivado na década de 1930 - como o voto feminino e a criação das primeiras universidades -, continuamos a ter os cárceres carregados de acusados por pecados de ideologia ${ }^{6}$. Da primeira metade do século passado até hoje, vivenciamos poucas décadas inteiras de experiência democrática, com exercício de poder civil sem golpe ou tutela militar. $\mathrm{O}$ autoritarismo correspondente à tradição oligárquica e à deficiência democrática tem sido contrário às reivindicações das classes trabalhadoras. No entanto, a questão social dos trabalhadores acompanha a industrialização, embora tenha chegado tarde e fez-se presente no século XX também no Brasil, estando no centro das experiências políticas democráticas, assim como no da motivação dos golpes reacionários.

Tomando como marco a conquista de direitos trabalhistas pela CLT em 1941, as relações dos trabalhadores com a vida política brasileira não foi poupada de conflitos, sucedendo-se uma história de contradições, com enfrentamentos entre as massas trabalhadoras, as classes desfavorecidas, as classes médias, e os grupos dominantes e elites de privilégios, com seus órgãos de repressão e presença no poder central da república. Falam de modo muito expressivo certas passagens da vida política brasileira na segunda parte do século XX, desde o fim do Estado Novo em 1945, com o afastamento do governo Vargas e sua substituição por um general ao gosto das potências estrangeiras; também a passagem de 1954, quando a pressão da imprensa conservadora levaria ao suicídio de Getúlio Vargas, embora tivessem ocorrido eleições democráticas que levaram à eleição de Juscelino Kubitschek em 1955. Vale também lembrar a passagem de 1961 quando, após a renúncia de Jânio Quadros, as forças conservadoras tentaram impedir que o vice-presidente Jango Goulart assumisse a presidência, mas a resistência popular, sobretudo de estudantes, operários e camponeses, com apoio de parte do exército e a liderança do então governador do Rio Grande do Sul, Leonel Brizola, conseguiu provisoriamente impedir, na verdade, transferiu por três anos o golpe conservador que se fez em defesa dos interesses do capital, contra a expressão da esperança dos trabalhadores nas reformas de base que prometia o governo trabalhista?.

Com o golpe militar de 31 de março de 1964, o país foi subjugado e teve de suportar mais de duas décadas de censura e repressão policial, até conseguir recuperar, embora imperfeitamente, os direitos políticos na luta pela redemocratização que se fortificou, em 1979, a partir da anistia. Não saberíamos abordar aqui, de modo suficiente e respeitoso, o capítulo dos subterrâneos da repressão política do tempo do regime militar, vinculado aos interesses da economia dependente que há séculos acarreta perdas e frustrações ao nosso país e a toda a América Latina pela submissão aos interesses do mercado capitalista mundial e ao poder imperial. Todavia, a urbanização, o desenvolvimento da indústria, a escolarização e a modernização do trabalho que ocorreram

6 Basta ler Memórias do cárcere, de Graciliano Ramos (1956).

7 Remeto a meu e-book Política e vocação brasileira: leituras transdisciplinares (Albornoz, 2015), em que tive oportunidade de abordar alguns aspectos da política brasileira nas páginas sobre o Brasil. 
no período de autoritarismo militar, com apoio da maioria silenciosa e da minoria crítica, das comunidades de base e entidades da sociedade civil, de setores da ciência, das alas mais progressistas das igrejas, da educação e da cultura possibilitaram avanços da consciência social e se mantiveram esperanças no meio dos grupos oprimidos.

A esperança se manteve acesa, embora sufocada e controlada, na classe trabalhadora da indústria, entre sindicalistas de diversas categorias profissionais, como a dos professores, trabalhadores da educação, e entre outros sujeitos sociais, em grupos de reflexão e ação do movimento feminista, do movimento negro, dos trabalhadores sem terra, de todos cuja situação estava condicionada pela exclusão ou inserção problemática no mercado de trabalho. A redemocratização que se iniciou após a anistia, com a volta de muitos brasileiros exilados, testemunhou um processo de florescimento de movimentos sociais os mais diversos que se fizeram ouvir na Assembleia Constituinte.

A restauração do poder civil e a volta ao funcionamento de três poderes republicanos, embora imperfeitos, contudo mais autônomos em relação à casta militar, parece ter-se tornado possível depois da promulgação da Constituição em 1988. A partir de então, nas últimas três décadas, deu-se a mais longa experiência democrática da nação brasileira que, esperemos, há de superar a crise atual e permanecer. De 1985 a 2016, vivemos nosso maior período de construção ou reconstrução política. E, para a história da esperança brasileira, com limites e desenganos, mas também com muitas realizações e aprendizagens, foi essencial a fundação do Partido dos Trabalhadores em 1980, sua paulatina afirmação até 1989 e o acesso a postos centrais da administração de algumas cidades, estados e do país em 2002.

Ainda não é o momento de avaliar com clareza o que foi construído nesse período, o que permanecerá e o que pode ser destruído, mas o tempo da vivência democrática desde 1985 e, especialmente, o da década dos governos do PT, de 2003 a 2015/2016, foi, sem dúvida, uma experiência inédita, extraordinária, para os brasileiros. É crucial manter a memória das conquistas do país neste período, das políticas sociais realizadas em favor da população mais pobre, sobretudo, dos trabalhadores; da superação da fome e da retirada de milhões de brasileiros da pobreza e da miséria; além disso, cabe reconhecer o trabalho desenvolvido no plano da saúde, da educação e da cultura, pelos direitos dos grupos tradicionalmente discriminados, conquistas no plano do combate a problemas tradicionalmente silenciados, como o do racismo, a homofobia, a repressão policial, pela afirmação dos direitos humanos; problemas que se juntam e permanecem a serem enfrentados. Embora não possamos comprovar o que dos direitos conquistados nas últimas décadas pelo povo brasileiro resistirá ao atual ataque reacionário à soberania do país, espero que tenha se construído uma nova confiança na cultura da população pela expansão da educação e da comunicação, em nossas próprias possibilidades que, segundo a minha esperança, florescerá e dará frutos numa próxima estação. Haveremos de aprender com essa queda e voltar a levantar a bandeira da utopia concreta de uma sociedade melhor no Brasil.

\section{Trabalho e esperança em 2020}

Neste início de século e milênio, tão claramente um tempo de transição e de incertezas, percebe-se o imenso desafio que está posto para a humanidade. Antes mesmo da crise da pandemia, subjacente à crise sanitária que, em âmbito mundial, se associa à crise econômica da forma de produção e promete mudanças de lugar dos principais protagonistas da cena planetária. Em nosso país, à vicissitude da pandemia, imbricada com a evolução econômica a rigor imprevisível, acresce uma crise política que evoca um espetáculo de circo à beira do abismo. Pois, neste momento, o desgoverno com ideário fascista ameaça a sobrevivência da população ao não coordenar em nível de país uma reação adequada para o combate da epidemia e, por outro lado, faz ameaças ao 
funcionamento das instituições republicanas e democráticas. Paradoxalmente eleito, representa um risco real para o convívio pacífico, pois estimula setores armados e lidera um retrocesso nas conquistas de desenvolvimento humano, enquanto promove um evidente processo de destruição de direitos, servindo sem pejo a interesses estrangeiros, ultraminoritários, do capitalismo financeiro, associado ao conservadorismo negador da ciência e defensor da ignorância e da desinformação.

Ante a nação brasileira em 2020, está posto um grande nó a ser desatado com urgência, que precisa ser entendido também em seus elos menos imediatos com as grandes transformações do trabalho, que ocorrem em nível planetário, devido às novas tecnologias e à automação. O evento imediato acentua e agrava o fenômeno de mais "longa duração". A revisão que possamos fazer aqui, de todo modo, terá muitas lacunas e não vai esgotar o assunto; deixará muitas questões de lado e outras em aberto. Este texto apenas procura ajudar a compreender tais elos mais amplos, complexos, do plano da esperança e da possibilidade futura, mais que da realidade atual.

Neste momento, o mundo todo está em crise e, nele, especialmente, o Brasil se encontra em uma conjuntura de muitas incertezas. Vivemos uma situação inegável de ameaça a muitas conquistas do último quarto de século, em termos de soberania nacional e de direitos de cidadania, de todos os cidadãos e das minorias, e também das conquistas de direitos dos trabalhadores, com riscos de retrocesso quanto a liberdades, reconhecimento e igualdade racial, de gênero, de cultura e de liberdade de religião. Não se tem uma perspectiva clara sobre como vai evoluir esta conjuntura tão delicada nos próximos anos, quando se encontra instalado um grupo despreparado para o exercício da autoridade democrática no governo da República, de ideologia de extrema direita que age como inimigo da democracia. Não se sabe como será possível retomar o caminho na direção da vida democrática, para procurar a melhoria da vida dos mais fracos - dos pobres, índios, negros, crianças, velhos e enfermos - que, evidentemente, não são a preocupação do atual grupo no poder.

A crise sanitária é negligenciada em plano nacional, deixada para responsabilidade dos governos estaduais e municipais, entregue à capacidade de reação espontânea, de resiliência e improvisação do povo brasileiro, em suas comunidades e famílias. A crise econômica, que avança sob a sanitária, gera receios para o futuro e transfere problemas do momento para situação posterior. Já a crise política, barulhenta e midiática, causa insegurança e desorientação que poderiam ser evitadas se houvesse uma ação governamental inteligente, com sensibilidade em relação à vida da maioria da população. Os eventos confirmam a incapacidade de administração da crise por parte do desgoverno obcecado com a manutenção do poder e o controle policial. O insólito das interferências de tal grupo na cena principal toma atenção da imprensa corporativa e de grande parte da atividade de debate, informação e reflexão na imprensa alternativa. As dificuldades imediatas se instalam dentro da mudança mais permanente que tem a ver com a transformação das formas de vida, em relação com as novas formas de tecnologia e trabalho, devido à automação e às novas tecnologias de produção e comunicação.

Impõe-se um imenso esforço para recuperar a condição mínima de convívio livre, em nome da soberania nacional, do respeito à Constituição, às instituições legais, para poder continuar a construir a nação, ainda tão carente do ponto de vista da educação e do desenvolvimento técnico e científico; para continuar a trabalhar pela construção de um país com menos desigualdade e sofrimento, com menos injustiças, menos violência, com melhores índices de desenvolvimento humano, no plano da economia e da convivência social ou política.

No Brasil e no mundo, a percepção de crise se enraíza em algo que a antecede devido às transformações tecnológicas do final do século XX. E rapidamente, conforme as áreas e os produtos, é preciso reconhecer, desenvolve-se um processo de desindustrialização, pelo menos, de diminuição da relevância da indústria como meio de trabalho e sobrevivência de grandes massas trabalhadoras. O salto tecnológico é fato global. No Ocidente capitalista, o capital predominante é o financeiro, não mais o produtivo, e o descaso dos governos neoliberais pelo bem-estar da população vulnerável

\section{0}


gera novas tensões e conflitos. Com maior automação e novas tecnologias, mesmo a produção de alimentos e a fabricação de utilidades básicas ocupam menor número de trabalhadores. Portanto, a tendência é crescer o desemprego e o subemprego, mesmo dos jovens em plena fase etária produtiva. Desemprego, subemprego, emprego informal, trabalho desprotegido, flexível, vulnerável, emprego parcial como desemprego parcial não são apenas um fenômeno econômico que afeta a forma de sobrevivência e convívio material da população. Tais formas de fragilização do trabalho e do emprego têm dimensões psicossociais e transformam as relações entre as categorias profissionais e as classes sociais com consequências relevantes nas dinâmicas políticas.

Nessa encruzilhada da infecção planetária, a virtualização do trabalho, que se estabelece como expediente para enfrentar a passagem da pandemia, acaba por estimular e acelerar uma tendência que a transcende e, com isso, criam-se novas formas de comércio e prestação de serviços mediante a mediação da internet. Em alguns setores, a virtualização é menos difícil, em outros é extremamente problemática, se não impossível, e, assim, estamos todos diante de um desafio imenso que nos leva a indagações ainda sem respostas.

Com a produção automatizada e, portanto, os empregos na indústria reduzidos numericamente, como se poderá providenciar a plena atividade para as novas gerações? Como se dará a atividade que provê o sustento e, ao mesmo tempo, satisfaz a necessidade de convívio, colaboração e reconhecimento? Nessas novas condições, o trabalho continuará a ser o centro da vida humana? Qual a esperança realista? Como podemos trabalhar na direção do que sonhamos para o Brasil? São muitas as incertezas e há perguntas que ainda não podem ser respondidas plenamente, mas podemos tentar colocar as perguntas devidas e refletir a respeito.

\section{O que nos é permitido esperar?}

Quando a produção dos bens materiais pela automação reduz a necessidade de trabalho vivo, substitui o trabalho presencial e provoca aumento do desemprego, essa não é uma situação sem saída que não possa ser enfrentada pelas sociedades, com criatividade, senso de responsabilidade social e sensibilidade humanitária. Mas, em uma situação de transformações tecnológicas e automação do trabalho, com consequências imediatas e mediatas no mercado de emprego, redobram-se as necessidades de planejamento, incentivo, organização e coordenação dos setores produtivos e serviços, o que exige a capacidade de atuação de uma rede de serviços públicos, um Estado atento, ativo e criativo, com disposições que fogem ao horizonte dos projetos neoliberais presentes.

É preciso manter a consciência de que o trabalho industrial - esse que diminui a exigência de força de trabalho pela alta automação -, não é o único âmbito da vida econômica, sequer o único âmbito da produção. Ainda no plano da produção material requerem-se sempre muitas obras, como no plano da construção habitacional ou para a infraestrutura, de caráter mais amplo; surgem novas atividades para o aperfeiçoamento dos recursos naturais; obras de saneamento e para a racionalização da energia, mesmo se o evento de 2020 não permite prever o quanto será transformado o setor de transporte, intercâmbio e turismo.

Certamente, haverá de manter-se, e poderá desenvolver-se de modo mais matizado e menos concentrador, o setor primário, agrícola e pastoril que, no Brasil, tende a manter sua relevância mesmo no comércio global, e cuja reforma pode responder e desafogar o desemprego urbano. Assim como também se mantém o setor tradicional, multifacetado, do comércio, junto ao artesanato, que sempre desabrocha e encontra novas formas, inclusive novas tarefas que abrem novas linhas de trabalho e emprego.

Por outro lado, deverá manter-se a atividade de administração das coisas comunitárias, dos bens públicos, das políticas públicas para o bem-estar da população, o que, neste momento de 
crise sanitária, demonstra a sua total necessidade de fortalecimento e expansão e ainda pode evoluir de forma criativa em prol do desenvolvimento humano. Os trabalhadores da saúde têm a oportunidade de mostrar o caráter essencial de sua atividade, e os trabalhadores da educação e da cultura também sabem que a sua atividade é essencial. Além da agricultura, do artesanato, do comércio e outros serviços e da administração e serviços de sentido social e público, requer-se pensar a questão em todas as suas dimensões ante a redução do emprego na produção industrial automatizada para poder enxergar as possibilidades e manter a esperança no futuro, especialmente a dos jovens.

\section{Uma tomada de consciência é necessária}

Diante do problema do desemprego, além das questões mais concretas e imediatas do plano da administração econômica, algumas tomadas de consciência parecem necessárias. Não desprezemos a força das infraestruturas e das condições econômicas, tão sujeitas aos jogos de egoísmo das classes dominantes e do poder geopolítico, da economia global. No nosso hemisfério, especialmente na América Latina ${ }^{8}$, sequer são apenas interesses de classe que nos condicionam, pois é muito estrangeiro o olho do chamado mercado, esse ente vago de que fala a mídia estabelecida e que, em última análise, representa o poder imperial global.

Tentemos ampliar nossa percepção do problema pela reflexão. Uma primeira tomada de consciência, diante da inevitável redução da predominância da indústria como oportunidade de emprego e renda, parece-me ser a de que, além da produção de bens materiais, a sociedade necessita de sujeitos ativos preparados e dedicados à produção de bens imateriais para a sua realização e para contribuir com o desenvolvimento nacional nos âmbitos da ciência, da pesquisa, da educação, do ensino, da cultura, das artes, da saúde, do desenvolvimento humano, do esporte, do lazer, da comunicação, sem que a ordem desses âmbitos indique uma escala de valor. A sociedade necessita de sujeitos capacitados para a produção qualitativa no plano do conhecimento e da cultura. Já faz alguns anos que os sociólogos e historiadores buscam e ensaiam o uso de denominações adequadas para as sociedades contemporâneas às vezes ditas, simplesmente, como pós-industriais, mas os entendidos hesitam entre chamá-las de sociedades tecnológicas, sociedades do espetáculo, sociedades do conhecimento, sociedades da comunicação ou, ainda, de outras maneiras que não pretendo esgotar.

Uma segunda tomada de consciência me parece necessária para superar-se a atual crise mundial com o desemprego na indústria - a de que a vida, tão ligada à aspiração de dignidade, não depende exclusivamente da produção de bens, sejam materiais ou imateriais, pois muito trabalho se realiza e há muito trabalho a fazer, humanamente muito necessário, em forma de cuidado. Não se trata propriamente de trabalho como poiesis, mas de trabalho como "cura". Muitas dessas ocupações de "cuidadores" estiveram tradicionalmente mais ligadas à atuação das mulheres e têm sido, ao longo de séculos ou milênios, realizadas no âmbito doméstico e, por isso, frequentemente não foram remuneradas, mas, em nosso tempo, perderam essa marca de exclusividade de gênero. A mudança de consciência das mulheres, seus avanços na educação e sua aspiração à autonomia forçaram o reconhecimento de muitos desses cuidados como trabalho profissional e socialmente necessário. O cuidado saiu do âmbito doméstico e familiar para o serviço profissional, interindividual e pessoal, comunitário ou público, abrindo-se um imenso caminho para a atividade humana cuja essência é cuidar. Cuidar das crianças, dos idosos, dos imaturos, dos enfermos, dos problemáticos, dos fracos,

8 Sobre a realidade e a história da América Latina, contento-me em indicar a leitura do já clássico e essencial As veias abertas da América Latina, do escritor uruguaio Eduardo Galeano (Galeano, 2010).

9 Recomendo o capítulo sobre o cuidado em A mulher: seus modos de ser, de aparecer, de existir, de Buytendijk (1946), traduzido pela Editora Ufpel em 2010. 
dos concidadãos vulneráveis que precisam de cuidado especial. O esforço do cuidado deve expandir-se, cada vez mais conscientemente, ao cuidado da natureza e do meio ambiente, que tanto carecem de cuidados, e ao patrimônio histórico e cultural que também tanto o necessita.

Uma terceira tomada de consciência favorece a resposta à crise do desemprego pela automação da indústria. Volto a recomendar a leitura da fenomenologia da ação tão bem desenhada por Hannah Arendt (1958/1981) em A condição humana ${ }^{10}$, quando a filósofa refere, além do labor, do esforço com o suor do corpo pela sobrevivência, como próprio da atividade do agricultor e, além do trabalho propriamente dito, produção ou poiesis, pelo qual se produzem objetos que nos transcendem e perduram para além de nossas vidas, como no fazer do escultor; e tão ou mais definidor da condição humana do que labor e poiesis, temos o apelo à práxis, à participação na comunidade, em toda a sua significação, com dignidade, para a ação política.

A crise do desemprego ou do subemprego é tornada ainda mais grave pela manutenção de preconceitos com relação à produção imaterial, aquela no plano da ciência e da cultura, bem como em relação às atividades de cuidado ou em relação à ação comunitária e política. Parece manter-se uma saudade da organização do trabalho e dos trabalhadores como existia no auge da era industrial. Essa saudade, esse senso de perda e desalento, é compreensível, quando se considera a influência social e política que podia existir na atuação dos operários, por exemplo, dos milhares de operários sindicalizados empregados em uma grande indústria, o que é difícil ocorrer na população dedicada a serviços e cuidados, muitas vezes individualizados, separados, como que atomizados. Mas suponho que a maior inquietude, a maior incerteza que atinge a esperança no futuro, reside na questão da garantia de renda para sobreviver com dignidade, quando não existem mais as grandes corporações empregadoras de multidões para a produção como havia há um século.

O que impede resolver o problema do desemprego e da garantia de meio de sobrevivência digna é a lógica do sistema capitalista que, ao manter as imensas, injustas, terríveis diferenças no plano do jogo financeiro o poder, um universo de números em um jogo inimaginável de valores elude a questão que deveria estar sempre no centro da preocupação pública, o da sobrevivência digna da multidão, de todos e de cada um. Por isso, o grande problema que traz a utopia - que espero seja concreta e possa tornar-se real - é o da renda básica para a sobrevivência digna, seja do desempregado como do trabalhador informal, do trabalhador imaterial sem remuneração ou do trabalhador cuidador do mais fraco que não lhe pode remunerar o serviço, ou seja, a garantia da renda básica universal.

Não sou dona dessa sugestão que, em nossos dias, nem soa original, pois já está bastante divulgada entre os analistas e comentadores na mídia corporativa e na internet. Neste momento da pandemia, quando, dada a excepcionalidade da situação, autorizam-se soluções extraordinárias; quando se exercitam tais soluções, embora como passageiras, talvez se possam operar experimentos e abrir caminho - esta é a minha esperança -, para soluções mais permanentes na direção da garantia da renda universal básica. Não somente para escapar do risco da epidemia, mas para escapar do retorno à fome, à mortalidade infantil e à miséria causada pelo sistema nesta transição sem perspectivas claras, em um mundo com imensas transformações na produção e ameaça de menos oferta de empregos. Dá oportunidade para acrescentar-se à reflexão também a consideração do tempo de descanso necessário, de ócio criativo, com necessidade de revisão da centralidade do trabalho para o conjunto da vida humana com dignidade. No Brasil, os partidos progressistas têm tido esse tipo de preocupação ${ }^{11}$.

Neste momento da pandemia, em continentes e países diferentes como o Reino Unido ou a Índia, mesmo forças políticas conservadoras, adeptas do ideário neoliberal que defende o Estado

10 Quem deseje pensar o trabalho inserido em uma compreensão mais ampla da ação humana vai ganhar muito com a leitura dessa obra muito especial.

11 Em particular, o senador Eduardo Suplicy (PT/SP) tem trabalhado na direção dessa conquista tão necessária. 
mínimo, de modo diverso e, ao mesmo tempo, similar porque determinado pela mesma crise sanitária, fazem a aprendizagem trágica da necessidade da assistência, ou melhor, da responsabilidade social, e lançam mão de recursos excepcionais, tomando medidas de sentido imediato - como o auxílio emergencial que, se pode ser explorado por oportunistas demagógicos para manter-se no poder, também leva à consciência da crucial necessidade dos serviços do Estado e permitem a esperança de que medidas de emergência se transformem em conquistas sociais mais permanentes.

\section{Esperança e imaginação na passagem de milênio}

O espírito da utopia não se limita a sugestões de políticas públicas nem se prende a medidas administrativas, legais ou burocráticas, pois a esperança é aliada da imaginação. Porém, para que a esperança possa dar forma à realidade e, ainda que parcialmente, o sonho possa efetivar-se, deve ter raiz na realidade. É preciso que, na realidade, se encontrem possibilidades reais, condições objetivas e subjetivas, para a realização do sonho. E, para haver condições subjetivas de efetivação da esperança, não basta o sonho individual, o sonho precisa inserir-se na realidade maior, no sonho coletivo, seja o sonho sonhado por um grande grupo social específico de excluídos, explorados, oprimidos, seja o sonho sonhado por uma nova classe social em busca de novos direitos, seja o sonho sonhado por uma geração, como no caso da juventude insatisfeita após uma guerra ou catástrofe.

O grande sonho coletivo pode ser o mito de uma nação, de um povo ou, pelo menos, requer que um numeroso grupo social se identifique com ele; por motivos autênticos, por algo próprio, como sua situação econômica, sua cultura de origem ou gênero, sua cor da pele, suas crenças, traços incontornáveis, embora delicados de abordar, e que, muitas vezes, são usados, justamente, como falsas razões da desigualdade e da opressão. Portanto, é problemático identificar onde transita o sonho coletivo capaz de realização, mas, mesmo assim, cabe-nos detectar a esperança da utopia concreta em que se esconde a possibilidade real de superação do momento obscuro do presente.

Ao revisar a história dos últimos cem anos, identifica-se uma evolução do sonho, daquele que carrega o espírito da utopia. Desde o século XIX e ainda no início do século XX, o grande coração do movimento utópico, seu núcleo central, o "sujeito da história" era a classe operária industrial, o proletariado transnacional, ao mesmo tempo sofredor e resistente, frágil e forte, porque numeroso e indispensável, diante do gigante da sociedade industrial capitalista. Para o filósofo da esperança a quem referimos no início deste ensaio, a utopia concreta do presente era o socialismo, o sonho da sociedade de igualdade e liberdade que garantiria os direitos dos trabalhadores e estabeleceria uma nova forma de vida, produtiva, moderna e justa. A utopia concreta predominante no século passado, sem dúvida, foi a sociedade socialista, a ser construída em países governados por representantes do proletariado, onde se realizaria a esperança de uma sociedade com seu centro na classe trabalhadora.

Concomitantemente, além e ao lado dos operários, outros grupos também lutaram por seus sonhos e necessidades, no imenso universo dos povos colonizados em que tremendas violências e sofrimentos continuaram as lutas de independência mal acabadas dos séculos XIX/XX e restaram - na Ásia de Mahatma Gandhi, na América Latina de Che Guevara, na África de Nelson Mandela -, em todas as lutas anticolonialistas em que a humanidade tem se debatido até hoje, nas franjas de exclusão e inserção dos povos do chamado "terceiro mundo" e no "quarto mundo" escondido dentro do primeiro, o dos negros, indígenas, excluídos e explorados, do Norte e do Sul. Mesmo no centro do Velho Mundo que se quer iluminista, depois de mais de um século da proclamação dos direitos do homem, nazismo e fascismo foram capazes de estabelecer um cenário infernal, realizando com perversa capacidade técnica o holocausto de milhões de seres humanos, 
tragédia que se concluiria com o terror indizível da bomba sobre Hiroshima - pelo que o historiador está cheio de razão ao chamar o século XX de "era dos extremos"12.

O sonho ideal de transformação da sociedade, com o surgimento de um homem novo e um novo nexo de convívio entre as classes, ou supressão das classes sociais, foi-se encaminhando para uma espécie de acomodação ao real da democracia realmente existente, que em nenhum lugar existiu perfeita ou por completo e que, em diversos graus e modos, aqui ou ali, tem tempos mais favoráveis, outros mais críticos, avança e regride, conquista e fracassa. Nessa imaginação e esperança, nessa utopia da democracia, ao mesmo tempo ideal e real, combinou-se, de várias formas, o sonho liberal com o social, instalando-se a contradição, mesmo o combate, nem sempre o equilíbrio entre este e aquele. Mas a esperança de conquista de direitos e melhorias de condição de trabalho continuou a animar as lutas sociais, seja nas fábricas ou nas estruturas de serviços que tomaram espaço às fábricas, nos países sob a exploração capitalista; e a esperança na melhoria de qualidade de vida dos trabalhadores provocou também tensões sociais nos países que experimentavam formas de economia socializada.

Nessas novas lutas da história das utopias sonhadas em grande grupo, além da classe operária, tomaram projeção outros sujeitos sociais que marcaram a época. Com bandeiras várias, com forte marca do pensamento crítico à sociedade burguesa - na busca de libertação sexual, por exemplo, os jovens da época, com grande impulso de vida, conjugaram muitas cores e sonhos na ebulição utópica. Na América Latina, no início da década de 1960, com a inspiração da revolução cubana vitoriosa em 1959, os estudantes se uniram aos operários e aos movimentos camponeses, conforme o país e a situação, em movimentos diversos, de libertação e de reformas ou promessas de reformas, que logo adiante foram reprimidos fortemente e submergidos pelos golpes da reação militar autoritária concertada entre as classes dominantes nacionais e o Norte. Nos Estados Unidos da América do Norte, a população negra, que obtivera vitórias históricas na sua luta pelos direitos civis, mas também derrotas como a que significou o assassinato de Martin Luther King, continuou a enfrentar corajosamente o racismo estrutural americano, assumindo a face forte dos Black Panthers. Naquele mesmo país, foram memoráveis os protestos contra a guerra do Vietnam em 1967-1968, quando também eram os jovens os principais envolvidos e atingidos, e quando os sonhadores que se chamaram hippies pediam "faça amor, não faça a guerra". Os jovens da época teriam também outra marcante expressão na revolta estudantil na Europa, sobretudo na França, quando os rebeldes de maio 1968 pediam "a imaginação no poder". Os jovens franceses se rebelavam contra o autoritarismo das instituições, da escola, da sociedade burguesa, da polícia abusiva e, com o seu movimento, chegaram a obter a adesão da classe trabalhadora, fazendo por um momento balançar o Estado estabelecido.

Inseridas nos movimentos progressistas e libertários, de um lado e outro do Atlântico, no século XX, destacou-se a inquietação e a esperança de emancipação das mulheres em luta por autonomia e reconhecimento social, sobretudo por meio do trabalho. A polêmica sobre o feminismo é farta e ainda não resolveu a inserção das mulheres na vida política, mas parece indubitável que a nova onda de feminismo tem sido um dos fenômenos sociais de caráter mundial mais importantes do século e que teve uma imensa influência sobre a participação feminina no universo do trabalho. O filósofo da esperança Ernst Bloch interpretou o movimento das mulheres dos séculos XIX/XX como uma "utopia burguesa de grupo" e, de modo muito instigante, o compreendeu como, em sua essência, uma "utopia da não violência"13. O feminismo teria a ver com o sonho, talvez não

12 Refiro-me a Era dos extremos: o breve século XX (1914-1991) de Eric Hobsbawn (1997), que li na tradução de Marcos Santarrita em 1997.

13 Expus Bloch sobre o feminismo em Ética e utopia (Albornoz, 2006) e em As mulheres e a mudança nos costumes: ensaios da igualdade e da diferença (Albornoz, 2008). Também nesse livro abordei outros filósofos sobre a personagem a que aludi também em outros textos, como "O exemplo de Antígona" (Albornoz, 1999). 
realizável, de superação da violência. No cerne da ideologia feminista, estaria um resquício da lei das mães, talvez uma sobra do matriarcado mítico do qual não se tem evidências científicas. $\mathrm{O}$ feminismo seria antigonal no sentido de inspirar-se nas "leis não escritas" evocadas por Antígona, a figura emblemática do mito grego e da tragédia de Sófocles que tem sido objeto de reflexão e análise por tantos filósofos em todas as épocas da história da filosofia ocidental, e cuja interpretação já clássica considera Antígona como encarnação da ética da família ${ }^{14}$.

Entendido como afirmação da "lei das mães", das leis "não escritas", de uma ética da não violência, do sangue e do coração, parece justo afirmar o caráter antigonal do sonho feminista, traço que mantém em comum com o pacifismo e a ecologia. Para essa interpretação, me parece corroborar a expressiva participação de mulheres nos movimentos dedicados à ecologia, pela conservação do meio ambiente e pela afirmação dos direitos humanos, em busca da superação da violência, das polícias repressivas e das guerras. Em Angela Davis, militante socialista, filósofa feminista e negra que, nos anos de 1968-1971, foi muito famosa e admirada, depois processada pelo Estado norte-americano, que a levou à prisão, experiência que marcou seus trabalhos posteriores sobre o problema do encarceramento e do trabalho forçado dos negros no seu país - que convida a refletir sobre as prisões no Brasil, percebe-se a junção das diversas lutas do século, das diversas bandeiras utópicas que tremularam nos ares dos movimentos sociais da segunda parte do século $\mathrm{XX}^{15}$.

\section{Trabalho, educação e esperança}

Nas últimas décadas do século passado e neste início de milênio, novos sonhos coletivos emergiram no Brasil e na América do Sul. É admirável que se tenha podido fundar um Partido dos Trabalhadores, que não permaneceu apenas um partido ideológico restrito e se transformou em um partido de massas, com um líder carismático da classe operária - Luiz Inácio Lula da Silva, com grande intensidade de organização e debate interno e quadros competentes distribuídos por todo o país. A esperança do PT soube fazer aliados nos demais meios progressistas, por afinidade ideológica ou pela solidariedade e proximidade nos movimentos sociais dos quais nasceu: dos sindicatos da indústria, em seus diversos setores e federações; do Movimento dos Trabalhadores Rurais sem Terra, cuja realização associa, de forma exemplar, trabalho, esperança e educação; dos artistas e pessoas animadoras da cultura; dos trabalhadores da educação, da saúde e de outros serviços urbanos; de técnicos e profissionais de áreas universitárias, como a arquitetura, as ciências humanas, o serviço social; das comunidades eclesiais de base; dos trabalhadores sem teto; de tantos focos de sonhadores com alma e impulso utópico, de modo que possui um lastro social consistente na sua origem ${ }^{16}$.

A experiência dos governos de partidos progressistas na América Latina no início deste milênio, como os do PT no Brasil, em certo momento, tornou-se um exemplo e motivo de esperança também para quem olhava o país desde fora ${ }^{17}$. Essa experiência deve manter forte nossa autoconfiança, para que possamos achar ânimo e determinação para superar a atual conjuntura política negativa. O Brasil enfrenta um ataque aos sonhos igualitários desenvolvidos nas décadas de redemocratização e dos governos de orientação popular: na área da ecologia, da proteção do meio ambiente, especialmente da Amazônia pelo controle do desmatamento; quanto ao respeito,

14 Sobre Antígona já expus em várias ocasiões. No capítulo VIII de As mulheres e a mudança dos costumes (Albornoz, 2008), referi interpretações de diversos filósofos sobre a personagem, a que aludi também em "O exemplo de Antígona" (Albornoz, 1999). Em 2020, tomo-a como tema em capítulo de livro organizado por Eunice Piazza Gai (Unisc).

15 A junção das lutas já é insinuada no título da sua obra Mulher, raça e classe (Davis, 2016).

16 Os trabalhos do sociólogo André Singer me parecem imprescindíveis para avaliar o significado do PT na história recente do Brasil.

17 Em fevereiro de 2005, encontrei uma vitrine de livraria em Paris com exposição exclusiva de títulos sobre experiências políticas inovadoras no Brasil, entre as quais a do orçamento participativo em Porto Alegre. 
reconhecimento e apoio ao MST; em relação ao respeito e reconhecimento do movimento negro, dos quilombolas e da liberdade de culto das religiões de matriz africana; quanto ao reconhecimento, à proteção e garantias aos descendentes dos povos originários, de modo a apoiar a conservação dos seus modos de vida e culturas.

A esperança aliada à confiança em nossas próprias capacidades de recuperação e organização política é a chama que temos de manter acesa apesar do vendaval, para continuar a tarefa que nunca termina de construção de uma sociedade com mais justiça - mais saudável e mais feliz, que hoje sofre sob o ataque do vírus planetário e também dos representantes do neoliberalismo colonialista estrangeiro, submisso ao capital financeiro e apoiado na inconsciência da elite nacional. Não sei como se dará a saída da armadilha em que o país resvalou, mas sei que há algo a ser mantido ativo, com vento a favor ou contra, que é o trabalho persistente de educação de nosso povo, de crianças e adultos sem distinção ${ }^{18}$.

O setor da educação, do cuidado das pessoas e da ajuda para seu crescimento, como o da cultura e o da ciência, estão sendo muito visados pelas forças retrógradas; nossas carências educacionais são grandes, mas precisamos resistir e não permitir a desmontagem do que conseguimos. Em 2019, foram muito expressivas as manifestações contra os ataques às estruturas educacionais, em defesa das escolas e das universidades, e as pautas do setor também têm obtido algumas vitórias favoráveis no âmbito do parlamento, o que me parece indicar que parte significativa do povo brasileiro mantém a consciência de que a educação condiciona sua melhoria de vida e nela deposita a sua esperança. Antes de terminar esta reflexão, gostaria de voltar à ideia tão célebre de Sérgio Buarque de Holanda de que o brasileiro pode ser entendido como um homem $\operatorname{cordial}^{19}$. Apesar de seus $\operatorname{críticos}^{20}$, a meu ver, esta é uma interpretação inspirada, e peço licença para dela fazer um uso enviesado, para afirmar que o homem cordial pode ser uma utopia concreta dos brasileiros. Gosto da sugestão de Buarque de Holanda mesmo entendendo cordialidade no seu sentido mais comum, sem a ambiguidade que o autor adota, porque ela me sugere a hipótese de que a cordialidade possa ser uma aspiração, um sonho de nós mesmos, espécie de utopia dos brasileiros - mas isso é outro assunto para outro texto ${ }^{21}$.

\section{Referências}

Albornoz, S. (1976). Por uma educação libertadora. Petrópolis, RJ: Vozes.

Albornoz, S. (1982). O jogo duplo do ensino. Porto Alegre: Movimento.

Albornoz, S. (1985). Ética e utopia: ensaio sobre Ernst Bloch. Porto Alegre: Movimento.

Albornoz, S. (1986). O que é trabalho. São Paulo: Brasiliense.

Albornoz, S. (1999). O enigma da esperança: Ernst Bloch e as margens da história do espírito. Petrópolis, RJ: Vozes.

Albornoz, S. (1999). O exemplo de Antígona. Porto Alegre: Movimento.

Albornoz, S. (2002). Violência ou não-violência: um estudo em torno de Ernst Bloch. Santa Cruz do Sul, RS: Edunisc.

18 Para compensar a falta de maiores referências sobre educação, remeto a meus livros das décadas de 1970 e 1980, como "Por uma educação libertadora" (Albornoz, 1976) e "O jogo duplo do ensino" (Albornoz, 1982), como também "O exemplo de Antígona" (Albornoz, 1999).

19 Ver "Raízes do Brasil" (Holanda, 1936/2010), sobretudo o capítulo V.

20 Respeito posição do sociólogo Jessé Souza que, se entendi bem, vê na intuição de Buarque de Holanda um engano hermenêutico do qual participam intelectuais brasileiros de todas as colorações ideológicas. Jessé tem razão, os brasileiros não somos somente simpáticos e educados, e ele sabe bem que não foi isso que escreveu o autor de "Raízes do Brasil". Jessé também tem razão que, ao considerarmos cordial o modo médio de ser do brasileiro, isso pode ter efeitos na consciência crítica e na responsabilidade política, pois pode levar-nos a esquecer a escravidão, o racismo, a repressão política, a violência policial etc. Ainda assim, o brasileiro como homem cordial me parece uma ótima inspiração utópica. A bibliografia sobre o tema é abundante, mesmo assim, ouso lembrar meu pequeno artigo "A utopia brasileira do homem cordial", previsto para publicação na revista Dialectus em 2020.

21 Tendo sido tema de conferência na UFPB, em João Pessoa, em 3 de dezembro de 2018, escrevi um pequeno artigo sobre essa ideia aceito para publicação na revista Dialectus - Revista de Filosofia, no 17 (2020.2) - Dossiê: Ernst Bloch. 
Albornoz, S. (2008). As mulheres e a mudança nos costumes: ensaios da igualdade e da diferença. Porto Alegre: Movimento. Albornoz, S. (2011). Trabalho e utopia na modernidade: de Thomas More a Paul Lafargue. Porto Alegre: Movimento.

Albornoz, S. (2015). Política e vocação brasileira: leituras transdisciplinares. São Leopoldo, RS: Editora Unisinos.

Arendt, H. (1981). A condição humana. Rio de Janeiro: Forense Universitária. (Originalmente publicado em 1958).

Bloch, E. (2005). O princípio esperança (Vol. 1, N. Schneider, trad.). Rio de Janeiro: Contraponto.

Bloch, E. (2006a). O princípio esperança (Vol. 2, W. Fuchs, trad.). Rio de Janeiro: Contraponto.

Bloch, E. (2006b). O princípio esperança (Vol. 3, N. Schneider, trad.). Rio de Janeiro: Contraponto.

Holanda, S. B. (2010). Raízes do Brasil. São Paulo: Schwarcz. (Originalmente publicado em 1936).

Buytendijk, F. J. J. (2010). A mulher: seus modos de ser, de aparecer, de existir. Pelotas, RS: Editora UFPEL. (Coleção Fepráxis). Davis, A. (2016). Mulher, raça e classe. São Paulo: Boitempo.

Galeano, E. (2010). Las venas abiertas de América Latina. Buenos Aires: Siglo Veintiuno.

Hobsbawn, E. (1997). Era dos extremos: o breve século XX (1914-1991) (M. Santarrita, trad.). São Paulo: Schwarcz.

Ramos, G. (1965). Memórias do cárcere (Vols. 1-2). São Paulo: Livraria Martins Editora.

\section{Endereço para correspondência}

albornoz.suzanaguerra@gmail.com
Recebido em: 30/6/2020

Aprovado em: 12/8/2020 